\title{
VITAMIN D DEFICIENCY IN RUSSIAN PREGNANT WOMEN AND RISK FOR GESTATIONAL DIABETES
}

\section{P.V. Popova', ${ }^{2}$, A.V. Dronova', E.R. Sadikova', M.P. Parkkinen', M.V. Bolshakova ${ }^{2}$,E.N. Grineva ${ }^{1},{ }^{2}$}

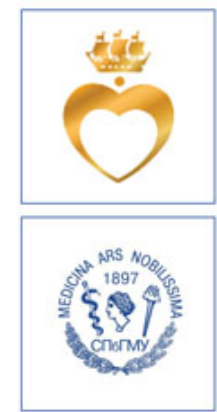

1 Almazov Federal Heart, Blood and Endocrinology Centre, St-Petersburg, Russia 2 The First Pavlov St Petersburg State Medical University. St-Petersburg. Russia

Corresponding author: pvpopova@yandex.ru

Introduction: Some, but not all, previously published studies suggest that low vitamin $\mathrm{D}$ status maybe associated with increased risk of gestational diabetes (GDM). We examined the association of plasma plasma 25-hydroxyvitamin D $(25(\mathrm{OH}) \mathrm{D})$ concentration with GDM risk and neonatal macrosomia.

Methods: 143 women were recruited before 15 weeks of gestation and were followed up until delivery. Maternal plasma $25(\mathrm{OH}) \mathrm{D}$ concentrations were measured at 8-14 weeks of gestation. 2-h 75-g oral glucose tolerance test (OGTT) was performed between 24 and 28 weeks of gestation. GDM was diagnosed according to IADPSG criteria. The neonatal anthropometry was also measured.

Characteristics of Pregnant Women with GDM and controls

\begin{tabular}{|c|c|c|c|}
\hline Variable & GDM Group & $\begin{array}{l}\text { Control } \\
\text { Group }\end{array}$ & $\boldsymbol{P}$ \\
\hline $\mathrm{N}$ & 19 & 124 & \\
\hline Age (years) & $32,3 \pm 4,8$ & $29,8 \pm 4,6$ & 0,046 \\
\hline Family history of T2DM & $44 \%$ & $35 \%$ & 0,442 \\
\hline Pre-BMI (kg/m2) & $25,6 \pm 4,9$ & $23,3 \pm 4,5$ & 0,045 \\
\hline Waist girth $(\mathrm{cm})$ at $8-14$ weeks & $87,0 \pm 12,0$ & $80,2 \pm 10,2$ & 0,024 \\
\hline FPG (mmol/L) at 8-14 weeks & $5,06 \pm 0,50$ & $4,74 \pm 0,59$ & 0,025 \\
\hline $25 \mathrm{OHD}(\mathrm{ng} / \mathrm{mL})$ at $8-14$ weeks & $21,8 \pm 8,5$ & $21,9 \pm 9,2$ & 0,983 \\
\hline Newborn's weight (kg) & $3,768 \pm 0,492$ & $3,458+0,537$ & 0,061 \\
\hline $\begin{array}{l}\text { Use of Vitamin D supplements } \\
\text { in the } 1^{\text {st }} \text { trimester }\end{array}$ & $21,4 \%$ & $18,8 \%$ & 0,729 \\
\hline $\begin{array}{l}\text { Use of Vitamin D supplements } \\
\text { by the time of OGTT }\end{array}$ & $57,1 \%$ & $56,3 \%$ & 1,00 \\
\hline
\end{tabular}

Note. GDM, gestational diabetes mellitus; DM, diabetes mellitus; BMI, body mass index; FPG, fasting plasma glucose; 25OHD, 25-hydroxyvitamin D OGTT, oral glucose tolerance test.
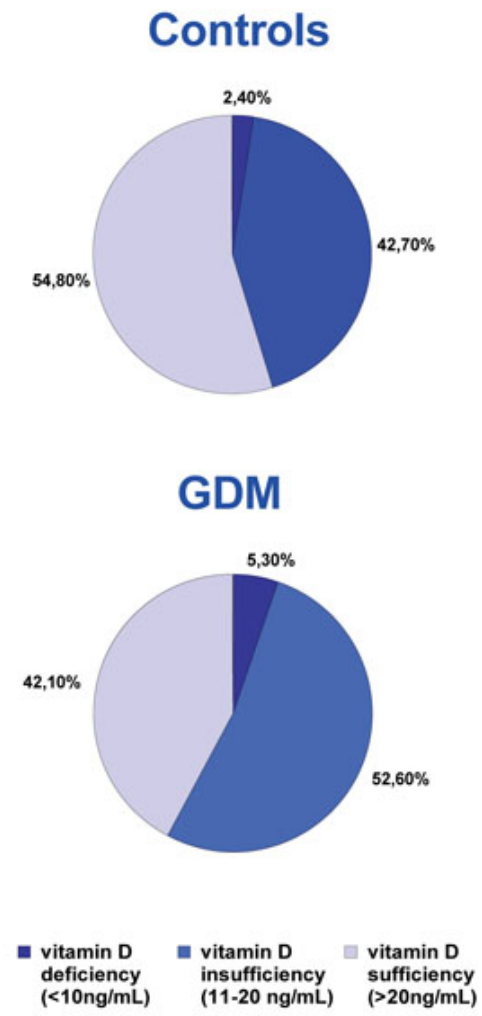

\section{Conclusion: Early pregnancy vitamin D deficiency and insufficiency were very common in the studied population of pregnant women. There was no association between maternal $25(\mathrm{OH}) \mathrm{D}$ and gestational diabetes.}

